\title{
Off-Label: Just What the Doctor Ordered
}

\author{
Christian Tomaszewski, MD
}

Carolinas Medical Center, Charlotte, North Carolina

You decide to give an old reliable therapy, intravenous $\mathrm{Mu}$ comyst ${ }^{\circledR}$, to an acetaminophen overdose patient rather than splurge on the new approved FDA formulation of the same drug, Acetadote ${ }^{\circledR}$. You administer octreotide, a medication approved for treating adverse effects of certain endocrine tumors, to a sulfonylurea overdose patient with recurrent hypoglycemia. You start an insulin infusion in a hypotensive verapamil overdose when norepinephrine infusion fails. In all three cases you are using drugs for indications not originally approved by the FDA. In other words, you are prescribing medications off-label. Is this bad medical practice? No, not necessarily. In fact you may be doing the right thing, as the standard of care changes for serious poisonings that require new, innovative treatments.

The Journal of Medical Toxicology will always have the opportunity to present case studies and therapeutic trials that promote off-label drug usage. Readers of cutting edge journals need studies regarding such usage. Recognition of a legitimate off-label use of a drug is delayed an average of 2.5 years from its appearance in the U.S. Pharmacopoeia Drug Information text [1]. Toxicologists have every right to recommend and use FDA unapproved therapeutic interventions provided they do it based on scientific evidence. In many cases, we are obligated to redefine the standard of care for serious poisonings.

By definition, off-label prescribing refers to the use of a drug for an indication, treatment regimen, or patient population not included in the FDA's originally approved labeling of the drug [2]. In addition, off-label use applies to treatment of variations of the original disease indication. For example, CroFab ${ }^{\circledR}$ is approved for only mild to moderate crotalid envenomation; so its use in severe envenomation, with decreased mental status and life-threatening bleeding, would be off-label [3]. A different treatment regimen is also considered off-label, such as extending an Acetadote ${ }^{\circledR}$ (N-acetylcysteine) infusion in toxic liver failure beyond the 21 hour regimen dictated in the package insert [4]. These are just a few examples of the prevalent off-label uses of antidotes.
One of the largest patient populations for off-label antidote use is children, a demographic group not usually addressed in the original FDA approval. Off-label drug use ranges $20-30 \%$ for inpatients and as a high as $60 \%$ in newborns [5,6]. Like most drugs, many antidotes are not specifically approved for pediatric use, usually due to a lack of age specific safety, dosing, and efficacy studies. Many drugs approved in adults can cause untoward effects in children: promethazine (respiratory arrest), tetracylcines (dental staining), chloramphenicol (gray baby syndrome) and propofol (infusion deaths). In its infinite wisdom, the FDA initially addressed this problem with Pediatric Rule 1994 that allowed establishment of pediatric indications based on extrapolation of adult data [7]. Subsequently, in 1997 the FDA arranged for extended marketing rights through the Food and Drug Administration Modernization Act [8]. This act provided 6 months of exclusive marketing to drug manufacturers if they submit convincing pediatric clinical trial data. Since that time, almost 120 drugs have been granted pediatric exclusivity [9]. Unfortunately, none of them are antidotes.

One would think that the use of an off-label drug would be a defiant act, flaunting FDA directives. However, even the U.S. Supreme Court has ruled that the "off-label usage of medical devices is an accepted and necessary corollary of the FDA's mission to regulate" [10]. They go on to state that health care practitioners can "prescribe or administer any legally marketed device to a patient" without limitation or interference. The Center for Drug Evaluation and Research confirms this stance, stating that "neither the FDA nor the Federal government regulate the practice of medicine," and "any approved product may be used by a licensed practitioner for uses other that those stated in the product label" [11]. In addition, physicians may discuss such uses in print or lecture without censure. As of 2004, the Accreditation Council for Continuing Medical Education has dropped requirements for disclosure when mentioning use of off-label drugs or products in CME activities [12]. When asked about the extent of the FDA's

Keywords: off-label, prescribing

Notes: There was no funding for this editorial.

Corresponding Author: Christian Tomaszewski, MD, Dept of Emerg Med, Carolinas Medical Center, Charlotte, NC 28203. Email: ctomaszewski@ carolinas.org 
ability to regulate speech concerning off-label uses, the FDA responded on-line with "Get your hands OFF the docs!" [13]

In advancing scientific medicine through off-label prescribing, physicians may even redefine what is considered appropriate treatment. In a case involving off-label use of terbutaline for premature labor, in spite of a bad outcome, the courts stated that the "off-label use of a [...] drug or device may even define the standard of care" [14]. Such use is not research or experimentation. If the primary intent of the clinician is to benefit the patient, rather than publish, then no Institutional Review Board or Investigational Drug Application is required [15]. The FDA recognizes that "off-label use is a well-established principle that has allowed doctors to discover new and beneficial uses" for previously approved drugs [14].

In multiple instances, courts have stated that the use of an offlabel drug does not in itself constitute malpractice. In the case of the myocardial infarction induced by off-label terbutaline for tocolysis, a state appellate court ruled that the off-label nature of the drug was immaterial to the case [14]. Likewise, the Minnesota Court of Appeals in 1997 stated that physicians did not have to disclose the off-label nature of their therapy [16]. The case involved screws approved by the FDA for long bone fractures, which were used off-label by orthopedists in spinal surgery. Plaintiffs, having sustained damages, charged physicians for negligence in failing to disclose and obtain consent for off-label therapy. The court ruled in the physicians' favor, concluding that off-label use in itself does not imply that a therapy is "unsafe, risky, novel, or untried." Physicians may safely prescribe any drug off-label provided they practice a standard of care based on sound evidence.

In the end, the FDA, the courts, and logic support that toxicologists may use any approved product or medication in any manner deemed clinically appropriate. And as a journal presenting cutting edge information, the Journal Medical Toxicology has an obligation to publish responsible peer-reviewed studies and case reports exploring off-label uses of FDA approved drugs. In toxicology, off-label use of a drug more often than not defines the standard of care. Toxicologists work independently of government scrutiny, using collective scientific exchange to advance our specialty responsibly. We, rest assured, can treat our patients well without infringements on our ability to practice quality, cutting edge medical care.

The author has no potential financial conflicts of interest to report.

\section{REFERENCES}

1. Beales, J. Howard, III. 1996. New Uses for Old Drugs. In Competitive Strategies in the Pharmaceutical Industry, edited by R. B. Helms, 281-305. Washington, D.C.: American Enterprise Institute for Public Policy Research.
2. Mehlman, MJ [webpage on the Internet]. Off-label prescribing. New York, NY: interMDnet Corporation. [updated 2005 May; cited 9 May 2006]. Available from: http://www. thedoctorwillseeyounow.com/articles/bioethics/offlabel_11.

3. Crofab [package insert]. Brentwood, TN: Protherics Inc; January 2006.

4. Acetadote [package insert]. Nashville, TN: Cumberland Pharmaceuticals; February 2006.

5. Roberts R, Rodriguez W, Murphy D, Crescenzi T. Pediatric drug labeling: Improving the safety and efficacy of pediatric therapies. JAMA 2003;290:905-911.

6. Hill P. Off license and off label prescribing in children: litigation fears for physicians. Arch Dis Child 2005;90:i17-i18.

7. Specific requirements on content and format of labeling for human prescription drugs: revision of "pediatric use" subsection in the labeling, 59 Federal Register 64240 (1994).

8. Regulations requiring manufacturers to assess the safety and effectiveness of new drugs and biological products in pediatric patients, 63 Federal Register 66631 (1998).

9. Federal Drug Administration [webpage on the Internet]. Approved active moieties to which FDA has granted pediatric exclusivity for pediatric studies under Section 505A of the Federal Food, Drug, and Cosmetic Act. Washington, D.C.: Federal Drug Administration [updated 23 March 2006; cited 9 May 2006]. Available from: http://www.fda.gov/cder/pediatric/ exgrant.htm

10. Buckman Co. v. Plaintiffs' Legal Comm. (98-1768) 531 U.S. 341 (2001);159 F.3d 817, reversed.

11. Center for Drug Evaluation and Research [webpage on the Internet]. Oncology Tools: A short tour. Washington, D.C.: Food and Drug Administration [update 17 January 2006; cited 9 May 2006]. Available from: http://www.fda.gov/cder/cancer/ tour.htm.

12. Accreditation Council for Continuing Medical Education [webpage on the Internet]. Ask ACCME. Standards for Commercial Support, 5: Content and Format Without Commercial Bias. ACCME [updated 2004; cited 9 May 2006]. Available from: http://www.accme.org/index.cfm/fa/faq.detail/category_id/ 2ae7d7bc-3bf4-47fa-9cc7-b75b6466c277.cfm.

13. Federal Drug Administration [webpage on the Internet]. Docket 02N-0209 - Request for comment on first amendment issues, Comment number: EC-9. Federal Drug Administration [update 28 May 2002; cited 9 May 2006]. Available from: http://www.fda.gov/ohrms/dockets/98fr/02N-0209-EC9.html.

14. Richardson v. Miller, No M1997-00205-COA-R3-CV, 2000 WI. 1157246 (Tenn. Ct. App. 16 Aug. 2000)

15. American Academy of Pediatrics Committee on Drugs. Uses of drugs not described in the package insert (off-label uses). Pediatrics 2002;110:181-183.

16. Femrite v. Abbott Northwestern Hospital, 568 N.W. 2d 535, 542 (Minn. Ct. App. 1997). 